\title{
BMJ Open Examining the pathways by which work-life balance influences safety culture among healthcare workers in Taiwan: path analysis of data from a cross-sectional survey on patient safety culture among hospital staff
}

Yvonne Tran, ${ }^{1}$ Hsun-Hsiang Liao, ${ }^{2,3}$ En-Hui Yeh (D) , ${ }^{2}$ Louise A Ellis (1) , ${ }^{4}$ Robyn Clay-Williams (D), Jeffrey Braithwaite (D) ${ }^{4}$

To cite: Tran Y, Liao H-H, Yeh $\mathrm{E}-\mathrm{H}$, et al. Examining the pathways by which work-life balance influences safety culture among healthcare workers in Taiwan: path analysis of data from a cross-sectional survey on patient safety culture among hospital staff. BMJ Open 2021;11:e054143. doi:10.1136/ bmjopen-2021-054143

- Prepublication history for this paper is available online. To view these files, please visit the journal online (http://dx.doi. org/10.1136/bmjopen-2021054143).

Received 20 July 2021 Accepted 11 October 2021
Check for updates

(C) Author(s) (or their employer(s)) 2021. Re-use permitted under CC BY-NC. No commercial re-use. See rights and permissions. Published by BMJ.

For numbered affiliations see end of article.

Correspondence to

Dr Hsun-Hsiang Liao;

shinglia012@gmail.com

\section{ABSTRACT}

Objective The aim of this study is to examine the pathways by which work-life balance influences safety climate in hospital settings.

Design A national cross-sectional survey on patient safety culture.

Settings Healthcare workers from 56 hospitals in Taiwan, covering three work settings: intensive care units, operation rooms and emergency departments.

Participants 14345 healthcare workers took part in the survey and were included in the present analysis.

Primary and secondary outcome measures The Safety Attitudes, Maslach's Burn-out Inventory and Work-life balance questionnaires were used to measure patient safety culture, teamwork, leadership, emotional exhaustion and work-life balance. Path analysis was conducted to determine the relationship between work-life balance and safety climate. We tested for mediating and moderating factors influencing this relationship.

Results The path between work-life balance and safety climate was found to be significant $(b=0.32, p<0.001)$ and explained through a serial mediation. This relationship was found to be mediated by emotional exhaustion followed by teamwork climate in a full mediation. Leadership factors such as identifying as a manager, moderated the indirect pathway between work-life balance and safety climate through teamwork climate (index of moderation: $b=0.083$, bias corrected $95 \% \mathrm{Cl}$ 0.044 to 0.120 ) but not through emotional exhaustion or the serial pathway. Subgroup analysis from non-managers on their perception of management was also found to moderate this relationship.

Conclusion We found work-life balance to be associated with safety climate through a fully mediated model. The mediation pathways are moderated by self-identified leadership and perceptions of leadership. Understanding the pathways on how work-life balance influences safety climate provides an explanatory model that can be used when designing effective interventions for implementation in system-based approaches to improve patient safety culture in hospital settings.

\section{Strengths and limitations of this study}

- Provides an explanatory model that can be used for a system-based approach to improve patient safety culture.

- Demonstrates the indirect relationship between work-life balance and safety climate.

- Performed through a cross-sectional survey, so perceptions are from one point in time only.

- An imbalance of managers and non-managers for the moderation models.

\section{INTRODUCTION}

Reducing errors and improving patient safety are important goals for providing quality healthcare in organisations worldwide. ${ }^{1}$ The introduction of quality improvement into healthcare has brought to attention the relevance of organisational culture for quality and safety improvements ${ }^{2}$ and promoting a culture of safety has become an important pillar for the patient safety movement. ${ }^{3}$ In a qualitative review, seven factors were identified to be essential for the promotion of a robust patient safety culture: leadership, teamwork, evidence-based practice, communication, learning, just culture and patientcentred care. ${ }^{4}$ Conversely, factors that may compromise patient safety included: ineffective teamwork, failed organisational processes and the physical and psychological overload of healthcare professionals. ${ }^{5}$ Having a high work overload often leads to work-life conflicts which in turn affects work place performance. ${ }^{6}$ There is growing concern for the psychosocial experiences of healthcare professionals, especially since healthcare is said to be at a tipping point with escalating 


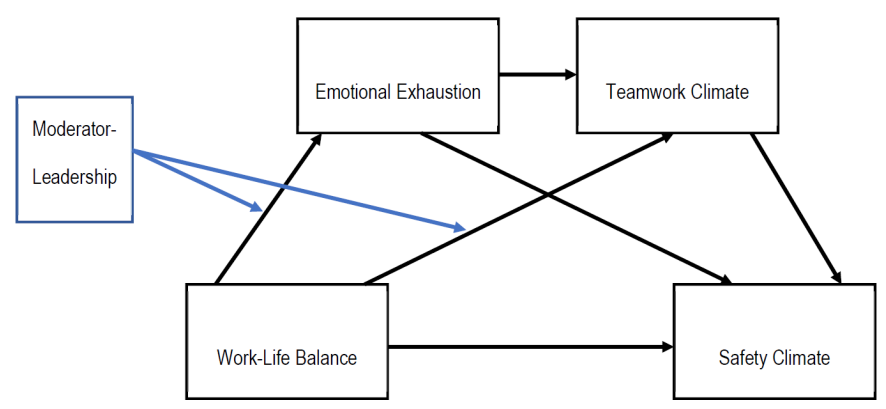

Figure 1 Hypothesised serial mediation model for worklife balance (WLB) and safety climate (SC) with leadership moderators. The direct relationship was between WLB and SC. The indirect relationships were: (1) WLB->emotional exhaustion (EE)->SC; (2) WLB->teamwork climate (TC) ->SC and (3) WLB>EE>TC>SC. Pathways are hereinafter expressed in abbreviated form (eg, WLB $>E E>S C$ ).

levels of burn-out and dissatisfaction with work-life balance (WLB) reported in healthcare workers. ${ }^{7}$ This is potentially putting the safety and quality of healthcare at risk.

Burn-out, characterised by emotional exhaustion (EE), depersonalisation and decreased personal accomplishment, is a psychological syndrome that occurs as a reaction to long-term exposure to stressful factors in the workplace. ${ }^{8}$ The increases of the prevalence of burn-out in healthcare professionals is reported to be occurring at considerable levels, and physicians in front line care, such as emergency medicine seem to be at greatest risk. ${ }^{9}$ High rates of burn-out are thought to be a result of high demanding work environments, long work hours and sleep deprivation. ${ }^{10}$ Burn-out is also thought to occur more frequently in all areas of healthcare that require face-to-face patient contact. ${ }^{11}$ Worryingly, the associations between burn-out and quality of care indicate lower perceptions of safety culture, increased medical errors and lower quality care. ${ }^{5712}$ For example, Al Balushi et $a l$ identified that self-reported medical errors by healthcare workers have a positive linear relationship with the degree of burn-out experienced. ${ }^{13}$

A prolonged work-life imbalance is thought to contribute to burn-out, with healthcare professionals often reporting both personal burn-out and dissatisfaction with work-life integration. ${ }^{7}$ WLB is defined as having satisfying experiences in all life domains, whereby personal resources are well distributed, with work overload often found to be a major contributing factor to conflicts in WLB. ${ }^{6}$ WLB is of particular concern as it has implications for not only the quality of work life but also has reciprocal spill-over effects on overall quality of life. ${ }^{14}$ To improve health and well-being, workplace health promotion requires a combined effort from employers, employees and society that focuses on creating a safe, motivating and enjoyable work setting. ${ }^{15}$ Little is known about the relationship between WLB behaviours, burn-out (specifically, EE), teamwork, leadership and patient safety culture and how these factors interact and interplay. By clarifying these relationships an explanatory pathway model for patient safety culture in hospital settings can be identified

The aim of this study was to examine the process by which WLB influences safety culture. Specifically, we aimed to:

1. Clarify through mediational processes, the pathways through which WLB influences safety climate (SC) in hospital settings. Through mediation analysis, the direct and indirect relationship between WLB and SC was examined.

SC was evaluated as it is often referred to as the measurable component of safety culture and encompasses management behaviours, safety systems and employee perceptions of safety. ${ }^{16}$

2. Investigate whether, and to what extent, the mediational process is conditional on leadership levels through a conditional process analysis of the interaction between leadership levels (self-identified as managers vs nonmanagers) and the mediation model.

3. Investigate whether the mediational process is conditional on perceptions of management (ie, staff approval of managerial action) in a subgroup of non-manager healthcare workers.

We hypothesised in our model that the relationship between WLB and SC can be explained through a serial mediation that is, WLB (or imbalance) contributes to $\mathrm{EE}^{7}$; $\mathrm{EE}$ is then a predictor for teamwork climate (TC) ${ }^{17}$; and TC is associated with SC. ${ }^{18}$ Given the importance of factors such as leadership in the promotion of a patient safety culture, we were interested in whether the hypothesised serial mediation model was conditional on leadership factors. We hypothesised that the indirect effects of the serial mediation model were conditional on the level of leadership and perceptions of management (see figure 1 for hypothesised model).

\section{METHOD}

\section{Study design and setting}

For this paper, we conducted secondary analysis using the Taiwan Patient Safety Culture Survey (TPSCS) dataset held by Joint Commission of Taiwan. The TPSCS dataset consisted of survey data from a cross-sectional study of Hospital Patient Safety Culture measured through a national survey administered to healthcare workers from hospitals in Taiwan. The survey was administered to healthcare workers from 92 hospitals in Taiwan from July to December during 2017. The survey sample was representative of the hospital systems in Taiwan. The 92 hospitals were located across all regions of Taiwan and comprised of three major types of hospitals: medical centres, regional hospitals and district hospitals. A census sampling technique was applied, that is, all staff members from participating hospitals were invited to participate. With each participating hospital, invitations were distributed by a hospital coordinator. Participation in the survey was on a voluntary basis and surveys were answered anonymously. 
Table 1 Demographic characteristics of respondents ( $N=14345)$ from three major work settings (ICU, ED, OR) of 56 hospitals

\begin{tabular}{|c|c|c|c|}
\hline Characteristics & Includes & $\mathbf{N}$ & $\%$ \\
\hline \multirow[t]{2}{*}{ Gender } & Male & 2497 & 17.4 \\
\hline & Female & 11848 & 82.6 \\
\hline \multirow[t]{6}{*}{ Age } & $<20$ & 100 & 0.7 \\
\hline & $21-30$ & 6281 & 43.8 \\
\hline & $31-40$ & 4581 & 31.9 \\
\hline & $41-50$ & 2473 & 17.2 \\
\hline & $51-60$ & 824 & 5.7 \\
\hline & $61+$ & 86 & 0.6 \\
\hline \multirow[t]{3}{*}{ Hospital type } & Medical centre & 8887 & 61.9 \\
\hline & Regional hospital & 5002 & 34.9 \\
\hline & District hospital & 456 & 3.2 \\
\hline \multirow[t]{3}{*}{ Work setting } & ICU & 7247 & 50.5 \\
\hline & ED & 3057 & 21.3 \\
\hline & OR & 4041 & 28.2 \\
\hline \multirow[t]{7}{*}{ Profession } & Physician & 1511 & 10.5 \\
\hline & Nurse & 11108 & 77.4 \\
\hline & Technologist & 721 & 5.0 \\
\hline & Pharmacist & 17 & 0.1 \\
\hline & Administrative & 580 & 4.0 \\
\hline & Rehabilitation staff & 3 & $<0.1$ \\
\hline & Other & 405 & 2.8 \\
\hline \multirow[t]{4}{*}{ Work type } & Full time & 12534 & 87.4 \\
\hline & Contract based & 1739 & 12.1 \\
\hline & Part time & 42 & 0.3 \\
\hline & Hourly based & 30 & 0.2 \\
\hline \multirow[t]{7}{*}{ Years (at hospital) } & $<6$ months & 902 & 6.3 \\
\hline & $6-12$ months & 457 & 3.2 \\
\hline & $1-2$ years & 2498 & 17.4 \\
\hline & $3-4$ years & 2449 & 17.1 \\
\hline & $5-10$ years & 3522 & 24.6 \\
\hline & 11-20years & 3201 & 22.3 \\
\hline & $20+$ years & 1316 & 9.2 \\
\hline \multirow[t]{4}{*}{ Education levels } & Junior high school & 65 & 0.5 \\
\hline & Senior high school & 345 & 2.4 \\
\hline & University & 12855 & 89.6 \\
\hline & Postgraduate & 1080 & 7.5 \\
\hline \multirow{3}{*}{$\begin{array}{l}\text { Level of patient } \\
\text { contact }\end{array}$} & Rare & 441 & 3.1 \\
\hline & Occasional & 776 & 5.4 \\
\hline & Often & 13128 & 91.5 \\
\hline \multirow[t]{2}{*}{ Manager } & Yes & 1133 & 7.9 \\
\hline & No & 13212 & 92.1 \\
\hline
\end{tabular}

ED, emergency department; ICU, intensive care unit; OR, operation rooms.

Since we were interested in the associations between WLB, EE and safety culture, we examined healthcare workers where these factors are more likely to be relevant.
For this study, we chose hospital departments that are known to be more strenuous and highly demanding, with greater exposure to: face-to-face contact with people, occupational hazards and greater levels of work stress. We, therefore, used a subset of the survey data, extracted from three major work settings: intensive care units (ICUs), emergency departments (ED) and operation rooms (OR). The demographic characteristics of the respondents from these three settings are shown in table 1.

\section{Survey and measures}

The survey was composed of demographic items (such as age, sex, profession and self-identification of rolemanager vs non-manager), the Safety Attitude Questionnaire (SAQ) and a personal burn-out assessment using the EE construct of Maslach's Burn-out Inventory and WLB items adapted from the College Activities and Behaviour Questionnaire. All three measures were adapted to Chinese-translated versions.

\section{Safety Attitude Questionnaire}

The SAQ-C is a Chinese translated version of the shortform SAQ (2006). ${ }^{19}{ }^{20}$ It is a 32-item self-report measure of six safety-related domains. The domains are: TC (perceptions of the quality of collaboration), SC (perceptions of organisational commitment to safety), job satisfaction (positivity regarding experience at work), stress recognition (acknowledgement of the role stressors play on performance), perceptions of management (staff approval for managerial actions) and working conditions (perceptions of the quality of work environment and logistical support).$^{20}$ The SAQ-C uses a five-point Likert scale ranging from strongly disagree (1) to strongly agree (5). The six domains are scored by taking the mean responses to the items in each domain, with higher scores indicating higher positive agreement in each domain. The SAQ-C has demonstrated validity and reliability, with Cronbach's alpha of $>0.7$ for each subscale. ${ }^{21}$

\section{Emotional exhaustion}

We used a modified derivative of the $\mathrm{EE}$ dimension ${ }^{22}$ from the Maslach's Burn-out Inventory. ${ }^{23}$ Although there are three dimensions for burn-out: EE, depersonalisation and decreased personal accomplishment, EE was chosen as it viewed as the core dimension of burn-out. ${ }^{23}{ }^{24}$ This dimension consists of nine items which measures feelings of EE resulting from fatigue, demands of the job and engagement with people. The EE dimension uses a five-point Likert scale ranging from strongly disagree (1) to strongly agree (5). The EE domain was scored by taking the mean of the nine items for each respondent, with higher scores indicating higher levels of EE. Reliability using Cronbach's alpha has been examined for the Maslach's Burn-out Inventory; the subscale EE has an alpha of $0.896 .{ }^{25}$

\section{Work-life balance}

We used the WLB items adapted from the College Activities and Behaviour Questionnaire and modified by Sexton 


\begin{tabular}{|c|c|c|c|}
\hline Measures & Mean & SD & $95 \% \mathrm{Cl}$ of mean \\
\hline \multicolumn{4}{|l|}{ SAQ domains } \\
\hline Teamwork climate & 3.90 & 0.78 & 3.89 to 3.92 \\
\hline Safety climate & 3.89 & 0.73 & 3.87 to 3.90 \\
\hline Job satisfaction & 3.77 & 0.86 & 3.75 to 3.78 \\
\hline Stress recognition & 3.66 & 0.70 & 3.65 to 3.67 \\
\hline $\begin{array}{l}\text { Perceptions of } \\
\text { management }\end{array}$ & 3.66 & 0.77 & 3.64 to 3.67 \\
\hline Working conditions & 3.31 & 0.80 & 3.29 to 3.32 \\
\hline Emotional exhaustion & 2.49 & 0.64 & 2.48 to 2.50 \\
\hline Work-life balance & 2.86 & 0.66 & 2.85 to 2.87 \\
\hline
\end{tabular}

et $a l^{26}$ This dimension has been psychometrically tested in healthcare workers in hospital settings. ${ }^{26}$ The WLB dimension consisted of seven items that reflect self-care and work-life norms. The WLB dimension uses a fourpoint Likert scale ranging from rarely or none of the time (less than 1 day per week) (1) to all of the time (5-7 days per week) (4). The WLB dimension was scored by taking the mean of the seven items for each respondent. Scores were then reversed so that higher scores indicated WLB, conversely, lower scores indicated work-life imbalance. The WLB dimension has been shown to have internal reliability of 0.79 using Cronbach's alpha. ${ }^{26}$

\section{Statistical analysis}

Descriptive statistics were conducted for each of the measures using SPSS V.25. ${ }^{27}$ Partial least squares path modelling was conducted to test for direct and indirect relationships between WLB and safety culture. Analyses were performed using the PROCESS procedure V.3.4 in SPSS V.25. ${ }^{28}$ From PROCESS, model 6 was used for the serial mediation model and model 84 for the moderated serial mediation models. Non-parametric bootstrapping analyses were used to test the models in this study. Mediation was found to be significant if the $95 \%$ bias corrected confidence intervals for the indirect effects did not include zero. To assess how much of an effect was meditated through the serial pathway we calculated the mediation proportion. Mediation proportion was defined as the proportion from the indirect effect (the mediator) on the total effects, that is the indirect effect divided by the total effect. ${ }^{29}$

Given the nested nature of the survey data, the variations in the path models may be due to variations at a higher level (unit or hospital level). All models were adjusted for hospital type and work settings. In addition, we included demographic variables as covariates to adjust for age, sex and profession differences in the respondents. The PROCESS procedure requires that analysis be conducted on a full dataset, therefore, a check for missing data was first conducted. All variables had less than $10 \%$ of survey data missing and missing data were imputed using the expectation maximisation technique. Common method bias was checked with the variance inflation factor (VIF). A VIF greater than 3.3 is indicative of common method bias in partial least squares path modelling. ${ }^{30}$

\section{Patient and public involvement statement}

No patients were involved in this study.

\section{RESULTS}

Between July and December of 2017, a total of 105443 survey invitations were issued from which 85410 valid questionnaires were returned from 92 hospitals, corresponding to a mean response rate of $81 \%$. A subset of 14345 responses, from the three major work settings of interest, consisting of data from 56 hospitals, was extracted for this study. Table 1 shows the demographic characteristics of a subset of survey respondents from the three major work settings (ICUs, EDs and OR) in the 56 hospitals. Table 2 shows the descriptive statistics for the survey measures.

\section{Model 1: serial mediation: WLB and SC}

First, common method bias was tested for the model using VIF. VIF for the variables ranged from 1.2 to 1.6 , therefore, the models were deemed not affected by common method bias. Results for the model were based on 5000 bootstrapped samples and showed a significant total effect $(\mathrm{b}($ total $))=0.32, \mathrm{SE}=0.009, \mathrm{p}<0.001)$. All three indirect pathways were found to be significant (see table 3 for details) but the direct effect between WLB and SC was not significant $(b($ direct $))=0.0013, \quad \mathrm{SE}=0.006, \mathrm{p}=0.81)$ indicating a full mediation. The two mediators, $\mathrm{EE}$ and TC fully mediated the relationship between WLB and SC, indicating that the relationship can be explained through this serial pathway (see figure 2).

\section{Model 2: moderated serial mediation model between self- identified managers and non-managers}

Moderation analysis was conducted to test whether the mediation effect from the serial mediation model was conditional on leadership levels (measured from respondents that identified as managers vs non-managers). The index of moderated mediation results showed that one of the indirect pathways ( $\mathrm{WLB}>\mathrm{TC}>\mathrm{SC}$ ) was conditional on the role of leadership, the other two indirect pathways (WLB $>\mathrm{EE}>\mathrm{SC}$ and $\mathrm{WLB}>\mathrm{EE}>\mathrm{TC}>\mathrm{SC}$ ) were not (see table 4). The indirect pathway WLB $>\mathrm{TC}>\mathrm{SC}$ was not significant for the group that self-identified as managers, indicating that, for this group, TC does not mediate the effects of WLB on SC. This indirect pathway was significant for the group that identified as non-managers, indicating the effects of this mediation path was stronger for non-managers and that TC was a significant factor in explaining the relationship between WLB and SC.

Model 3: moderated serial mediation model in non-managers subgroup for differing levels of perceptions of management Given differences between managers and non-managers in mediation pathways, we tested for whether the 
Table 3 Indirect effects for the three indirect pathways explaining the relationship between work-life balance (WLB) and safety climate (SC)

\begin{tabular}{lllll}
\hline Serial-mediation pathway & Indirect effect & SE & $\mathbf{9 5 \%} \mathbf{C l}$ & Mediation proportion \\
\hline WLB $>$ EE $>$ SC & 0.094 & 0.004 & 0.086 to 0.101 & 0.297 \\
WLB $>$ TC>SC & 0.053 & 0.006 & 0.040 to 0.066 & 0.165 \\
WLB>EE $>$ TC>SC & 0.170 & 0.005 & 0.161 to 0.179 & 0.536 \\
\hline
\end{tabular}

Bias-corrected bootstrapping was used.

$\mathrm{EE}$, emotional exhaustion; TC, teamwork climate.

mediation pathways are also conditional on perceptions of management in the subgroup of respondents that were non-managers. The index of moderated mediation results indicated that two indirect pathways were conditional on the perceptions of leadership for healthcare staff that did not identify as managers. Since the perceptions of management dimension was measured from a continuous variable, the moderation effects were tested for scores at the 16th 50th and 84th percentiles. This was equivalent to perceptions of management scores of 3.0, 3.75 and 4.5, respectively. The pathway WLB $>\mathrm{EE}>\mathrm{SC}$ and WLB $>\mathrm{EE}>\mathrm{TC}>\mathrm{SC}$ was conditional on the different levels from perceptions of management scores, whereas the index of moderation was not significant for the WLB $>$ TC $>$ SC pathway (see table 5). These mediation pathways were stronger for those that had higher perceptions of management, whereas, at lower levels of perceptions of management the mediation for WLB $>\mathrm{TC}>\mathrm{SC}$ was stronger. With higher scores in perceptions of management, there is a greater reliance on EE in explaining the relationship between WLB and SC.

\section{DISCUSSION}

Patient SC, teamwork, leadership, burn-out and WLB are thought to be central not only to understanding patient safety but keeping patients safe. Understanding how these concepts interact and interplay will allow for more targeted interventions or system-based approaches for patient safety improvements through organisation culture changes. For example, it has been proposed that medical errors can be reduced through interventions that address issues such as staff well-being and work unit safety. ${ }^{31}$ This study examined the relationship between WLB, staff burn-out, TC and patient SC to find an explanatory model for patient safety culture. We focused on

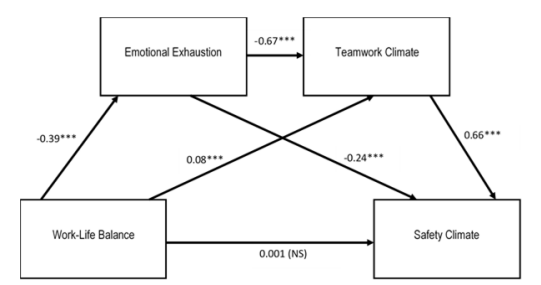

Figure 2 Serial mediation pathway for work-life balance and safety climate with regression coefficients $(B) .{ }^{* \star *} \mathrm{P}<0.001$. NS, not significant. survey responses from three major work settings (ICU, $\mathrm{ED}, \mathrm{OR}$ ) where there are greater levels of work stress and occupational hazards.

We found WLB to be associated with SC through a fully mediated model, with serial mediation through EE and TC. The mediation proportion for this pathway was 0.536 , indicating that over one half of the effect of WLB on SC can be explained by poor WLB leading to an increase in EE that, in turn, would affect TC and hence lead to impacts on SC. Our explanatory model supports the notion that a prolonged work-life imbalance significantly contributes to EE, with lower levels of WLB associated with higher levels of EE. For healthcare workers, increases in work demand, longer working and shift hours, and staff shortages have often led to imbalances between work and personal life. ${ }^{32}$ This work-life 'conflict' has been found to be a risk factor for work stress and burn-out For high work stress hospital departments such as ICUs, burn-out not only affects the health and welfare of professionals but also the provision of high-quality care. The relationship between WLB and EE in our model indicates that paying attention to one's personal life can perhaps be protective against burn-out symptoms. ${ }^{33}$ This relationship was also demonstrated in a study from Kok $e t a b^{4}$ which showed a mediational relationship between moral distress and EE and suggested that morally distressing events in the ICU could carry over to staff member's private life and, in turn, contribute to EE.

Through serial mediation, our model showed that higher EE was found to be a predictor for poor TC. Other prior studies have found poor TC to be associated with high intention to leave and high turnover, which has implications for interventions to target TC. ${ }^{35} 36$ Studies have also found that burn-out affects the level of engagement in work teams. ${ }^{37}$ Our explanatory model supports the notion that improving $\mathrm{EE}$ in healthcare may lead to improve TC. In this model, TC was found to be positively associated with SC, that is, when collaboration between staff members is perceived as high quality, perceptions of organisational commitment to safety are also strong. Overall, we demonstrated that WLB has an impact on SC, through the EE and TC pathways.

The quality of the relationship between leaders and their staff is thought to be key in fostering safety culture. ${ }^{4}$ We investigated whether the indirect pathways were conditional on leadership levels and perceptions of 
Table 4 Indirect effects for the three indirect pathways explaining the relationship between work-life balance (WLB) and safety climate (SC) with the leadership groups moderator

\begin{tabular}{lclcl}
\hline Moderated-mediation pathway & Indirect effect & SE & Lower $\mathbf{C l}$ & Upper Cl \\
\hline Manager: WLB>EE>SC & 0.106 & 0.009 & 0.089 & 0.123 \\
Non-Manager: WLB>EE>SC & 0.093 & 0.004 & 0.085 & 0.100 \\
Index of moderated mediation & -0.013 & 0.008 & -0.029 & 0.003 \\
Manager: WLB>TC>SC & -0.022 & 0.019 & -0.058 & 0.015 \\
Non-manager: WLB>TC>SC & 0.061 & 0.007 & 0.048 & 0.074 \\
Index of moderated mediation & 0.083 & 0.020 & 0.044 & 0.120 \\
Manager: WLB>EE>TC>SC & 0.188 & 0.014 & 0.161 & 0.216 \\
Non-manager: WLB>EE>TC>SC & 0.166 & 0.005 & 0.156 & 0.175 \\
\hline Index of moderated mediation & -0.023 & 0.014 & -0.051 & 0.005 \\
\hline
\end{tabular}

95\% Cl (two tailed).

Bias-corrected bootstrapping was used.

$\mathrm{EE}$, emotional exhaustion; TC, teamwork climate.

management. We found a significant moderation effect between those staff members who identified as managers and those who did not, for the path WLB $>$ TC $>$ SC. For managers, this path was not a significant indirect pathway in explaining the relationship between WLB and SC. The mediation effect for TC is significant for non-managers demonstrating stronger reliance on $\mathrm{TC}$ to mediate the effects between WLB on SC. In a subgroup of nonmanagers, the indirect pathways were also conditional on different levels of perceptions of management. There were significant moderation effects for both the indirect path $\mathrm{WLB}>\mathrm{EE}>\mathrm{SC}$ and $\mathrm{WLB}>\mathrm{EE}>\mathrm{TC}>\mathrm{SC}$. The mediation effects were stronger with higher levels of perceptions of management. Overall, the moderation analysis supports the result that there is a reliance on TC to mediate the relationship between WLB and SC among those staff members who do not identify as managers and those with lower perceptions of management. Among those with leadership roles or when perceptions of management are high, it is EE that is a stronger explanatory factor in the influence between WLB and SC.

Our findings indicate that support from leaders is necessary and without this staff will need to rely more heavily on teamwork. Similarly, in another study, support from direct supervisors was found to be beneficial in preventing adverse consequences of moral distress on

Table 5 Indirect effects for the three indirect pathways explaining the relationship between work-life balance (WLB) and safety climate (SC) with the perceptions of leadership moderator

\begin{tabular}{lllll}
\hline Moderated-mediation pathway & Indirect effect & SE & Lower $\mathbf{C l}$ & Upper $\mathbf{C l}$ \\
\hline Path: WLB>EE>SC & & & & 0.029 \\
\hline Perception of management: 16th & 0.034 & 0.002 & 0.041 & 0.050 \\
\hline Perception of management: 50th & 0.046 & 0.002 & 0.051 & 0.063 \\
\hline Perception of management: 84th & 0.057 & 0.003 & 0.011 & 0.020 \\
\hline Index of moderated mediation & 0.015 & 0.002 & & 0.034 \\
\hline Path: WLB>TC>SC & & & 0.036 & 0.025 \\
\hline Perception of management: 16th & 0.019 & 0.008 & 0.004 & 0.024 \\
\hline Perception of management: 50th & 0.015 & 0.005 & -0.002 & 0.007 \\
\hline Perception of management: 84th & 0.010 & 0.007 & -0.019 & 0.021 \\
\hline Index of moderated mediation & -0.006 & 0.007 & & 0.015 \\
\hline Path: WLB>EE>TC>SC & & & 0.020 & 0.027 \\
\hline Perception of management: 16th & 0.018 & 0.002 & 0.025 & 0.034 \\
\hline Perception of management: 50th & 0.024 & 0.002 & 0.006 & 0.011 \\
\hline Perception of management: 84th & 0.030 & 0.002 & & \\
\hline Index of moderated mediation & 0.008 & 0.001 & & \\
\hline
\end{tabular}

Bias-corrected bootstrapping was used.

$\mathrm{EE}$, emotional exhaustion; TC, teamwork climate. 
EE. ${ }^{34}$ The current explanatory model from our study shows how these concepts interplay and may enable the design of effective interventions for patient safety. For example, commitment to WLB as a cultural norm is thought to occur only if it is supported by leaders and co-workers indicating that it is more of a group-level norm. Interventions that target behaviours associated with WLB may lead to benefits if they are implemented at a work setting level rather than at an individual level. ${ }^{7}$ Improving WLB at a work setting level will then in turn lead to improvements in safety culture.

\section{LIMITATIONS}

The explanatory model for WLB and SC was performed through a cross-sectional survey; as such, one limitation is that it is based on the perceptions of safety culture from healthcare staff at one point in time. While the model explains the mediating and moderating effects of EE, TC and perceptions of management between WLB and safety culture, it does not demonstrate the impact of these factors on measurements of patient safety such as medical errors. However, patient safety culture is thought to be central to patient safety with implications that interventions for organisational cultures can be used as systembased approaches to improve patient safety. Another limitation is that the Maslach's Burn-out Inventory was adapted for the purpose of the national survey, as such it was not administered in the same way as originally intended. We did not obtain other burn-out dimensions which could be of interest. Given the importance of burn-out in this model, further research in this area is needed. The imbalance in the proportion of those that identify as managers $(7.9 \%)$ and non-managers for the moderation models is also a limitation. However, this is an accurate reflection and representative of the healthcare worker population in Taiwan. A balanced sample would require oversampling and would not be representative. An imbalance in the groups generally leads to an underestimation of moderating effects, thus moderating effects between leadership levels may have been underestimated. Lastly, the data for the model were obtained from a national survey from Taiwan; hence the findings may not be generalisable to other patient safety culture settings elsewhere.

\section{CONCLUSIONS}

WLB was found to be associated with SC in healthcare workers from 56 hospitals in Taiwan. The relationship between WLB and safety culture was best explained through a serial mediation model, where WLB is associated with $\mathrm{EE}$, which in turn predicts $\mathrm{TC}$ which then predicts SC. The serial mediation effect was found to be stronger with increasing levels of perceptions of management (ie, staff approval for managerial actions) Understanding the relationship between these factors provides an explanatory model that can be used for the implementation of effective interventions for a systembased approach to improve patient safety culture.

\section{Author affiliations}

${ }^{1}$ MU Hearing, Department of Linguistics, Macquarie University, Sydney, New South Wales, Australia

${ }^{2}$ Joint Commission of Taiwan, Banciao, Taiwan

${ }^{3}$ Departmment of Health Care Management, National Taipei University of Nursing and Health Sciences, Taipei, Taiwan

${ }^{4}$ Australian Institute of Health Innovation, Macquarie University, Sydney, New South Wales, Australia

\section{Twitter Robyn Clay-Williams @RClaywilliams}

Contributors The study was conceived by $\mathrm{YT}, \mathrm{E}-\mathrm{HY}$ and $\mathrm{H}-\mathrm{HL}$ and the study design was developed by YT, E-HY and H-HL. E-HY undertook data acquisition and data wrangling. YT performed the statistical analysis and YT, E-HY, H-HL, LAE, RC-W and $J B$ were involved with interpretation of the data. YT produced the first draft of the paper and E-HY, H-HL, LAE, RC-W and JB provided critical and substantial revisions to the manuscript. All authors approved the submitted version of the manuscript. $\mathrm{H}-\mathrm{HL}$ is responsible for the overall content as the guarantor.

Funding The authors have not declared a specific grant for this research from any funding agency in the public, commercial or not-for-profit sectors.

Competing interests None declared.

Patient and public involvement Patients and/or the public were not involved in the design, or conduct, or reporting, or dissemination plans of this research.

\section{Patient consent for publication Not applicable.}

Ethics approval This study was approved by The Institutional Review Board (IRB) of theNational Cheng Kung University Hospital. The analysis of determining factors to patient safety culture in Taiwan,Ethics ID: B-ER-109-324-T.

Provenance and peer review Not commissioned; externally peer reviewed.

Data availability statement № data are available. No additional data are available.

Open access This is an open access article distributed in accordance with the Creative Commons Attribution Non Commercial (CC BY-NC 4.0) license, which permits others to distribute, remix, adapt, build upon this work non-commercially, and license their derivative works on different terms, provided the original work is properly cited, appropriate credit is given, any changes made indicated, and the use is non-commercial. See: http://creativecommons.org/licenses/by-nc/4.0/.

\section{ORCID iDs}

En-Hui Yeh http://orcid.org/0000-0003-3127-0495

Louise A Ellis http://orcid.org/0000-0001-6902-4578

Robyn Clay-Williams http://orcid.org/0000-0002-6107-7445

Jeffrey Braithwaite http://orcid.org/0000-0003-0296-4957

\section{REFERENCES}

1 Jia PL, Zhang LH, Zhang MM, et al. Safety culture in a pharmacy setting using a pharmacy survey on patient safety culture: a crosssectional study in China. BMJ Open 2014;4:e004904.

2 Speroff T, Nwosu S, Greevy R, et al. Organisational culture: variation across hospitals and connection to patient safety climate. Qual Saf Health Care 2010;19:592-6.

3 Nieva VF, Sorra J. Safety culture assessment: a tool for improving patient safety in healthcare organizations. Qual Saf Health Care 2003;12:ii17-23.

4 Sammer CE, Lykens K, Singh KP, et al. What is patient safety culture? A review of the literature. J Nurs Scholarsh 2010;42:156-65.

5 Garcia CdeL, Abreu LCde, Ramos JLS. Influence of burnout on patient safety: systematic review and meta-analysis. Medicina 2019;55:1. doi:10.3390/medicina55090553

6 Poulose S, Sudarsan N. Assessing the influence of work-life balance dimensions among nurses in the healthcare sector. $J$ Manag Dev 2017;36:427-37. doi:10.1108/JMD-12-2015-0188

7 Schwartz SP, Adair KC, Bae J, et al. Work-life balance behaviours cluster in work settings and relate to burnout and safety culture: a cross-sectional survey analysis. BMJ Qual Saf 2019;28:142-50. doi:10.1136/bmjqs-2018-007933 
8 Maslach C. Job burnout: new directions in research and intervention. Current Directions in Psychological Science 2003;12:189-92.

9 Shanafelt TD, Boone S, Tan L, et al. Burnout and satisfaction with work-life balance among US physicians relative to the general US population. Arch Intern Med 2012;172:1377-85. doi:10.1001/ archinternmed.2012.3199

10 Klein J, Grosse Frie K, Blum K, et al. Burnout and perceived quality of care among German clinicians in surgery. Int J Qual Health Care 2010;22:525-30. doi:10.1093/intqhc/mzq056

11 Operating room nurses burnout and safety applications 2015

12 Hall LH, Johnson J, Watt I, et al. Healthcare staff wellbeing, burnout, and patient safety: a systematic review. PLoS One 2016;11:e015 9015-e15. doi:10.1371/journal.pone.0159015

13 Al Balushi AA, Alameddine M, Chan MF, et al. Factors associated with self-reported medical errors among healthcare workers: a crosssectional study from Oman. Int J Qual Health Care 2021;33:mzab102. doi:10.1093/intahc/mzab102

14 Guest DE. Perspectives on the study of work-life balance. Social Science Information 2002;41:255-79. doi:10.1177/0539018402041002005

15 Ejlertsson L, Heijbel B, Ejlertsson G, et al. Recovery, work-life balance and work experiences important to self-rated health: a questionnaire study on salutogenic work factors among Swedish primary health care employees. Work 2018;59:155-63. doi:10.3233/ WOR-172659

16 Colla JB, Bracken AC, Kinney LM, et al. Measuring patient safety climate: a review of surveys. Qual Saf Health Care 2005;14:364-6. doi:10.1136/qshc.2005.014217

17 García-Campayo J, Puebla-Guedea M, Herrera-Mercadal P, et al. Burnout syndrome and Demotivation among health care personnel. managing stressful situations: the importance of teamwork. Actas Dermosifiliogr 2016;107:400-6. doi:10.1016/j.adengl.2016.03.003

18 Manser T. Teamwork and patient safety in dynamic domains of healthcare: a review of the literature. Acta Anaesthesiol Scand 2009;53:143-51. doi:10.1111/j.1399-6576.2008.01717.x

19 Lee W-C, Wung $\mathrm{H}-\mathrm{Y}$, Liao $\mathrm{H}-\mathrm{H}$, et al. Hospital safety culture in Taiwan: a nationwide survey using Chinese version safety attitude questionnaire. BMC Health Serv Res 2010;10:234. doi:10.1186/14726963-10-234

20 Sexton JB, Helmreich RL, Neilands TB, et al. The safety attitudes questionnaire: psychometric properties, benchmarking data, and emerging research. BMC Health Serv Res 2006;6:44. doi:10.1186/1472-6963-6-44

21 Zhao C, Chang Q, Zhang X, et al. Evaluation of safety attitudes of hospitals and the effects of demographic factors on safety attitudes: a psychometric validation of the safety attitudes and safety climate questionnaire. BMC Health Serv Res 2019;19:836. doi:10.1186/ s12913-019-4682-0

22 Sexton JB, Adair KC. Forty-five good things: a prospective pilot study of the three good things well-being intervention in the USA for healthcare worker emotional exhaustion, depression, work-life balance and happiness. BMJ Open 2019;9:e022695. doi:10.1136/ bmjopen-2018-022695
23 Maslach C, Jackson SE. The measurement of experienced burnout. J Organ Behav 1981;2:99-113. doi:10.1002/job.4030020205

24 Welp A, Meier LL, Manser T. Emotional exhaustion and workload predict clinician-rated and objective patient safety. Front Psychol 2014;5:1573. doi:10.3389/fpsyg.2014.01573

25 Loera B, Converso D, Viotti S. Evaluating the psychometric properties of the Maslach burnout Inventory-Human services survey (MBI-HSS) among Italian nurses: how many factors must a researcher consider? PLoS One 2014;9:e114987-e87. doi:10.1371/ journal.pone.0114987

26 Sexton JB, Schwartz SP, Chadwick WA, et al. The associations between work-life balance behaviours, teamwork climate and safety climate: cross-sectional survey introducing the work-life climate scale, psychometric properties, benchmarking data and future directions. BMJ Qual Saf 2017;26:632-40. doi:10.1136/ bmjqs-2016-006032

27 Corp IBM. IBM SPSS statistics for windows, version 25. Armonk, NY: IBM Corp, 2017.

28 Hayes AF. Introduction to mediation, moderation, and conditional process analysis. In: A regression-based approach. 3rd edn. New York: Guildford Press, 2018.

29 Ditlevsen S, Christensen U, Lynch J, et al. The mediation proportion: a structural equation approach for estimating the proportion of exposure effect on outcome explained by an intermediate variable. Epidemiology 2005;16:114-20. doi:10.1097/01.ede.0000147107. 76079.07

30 Kock N. Common method bias in PLS-SEM: a full collinearity assessment approach. Journal of e-Collaboration 2015;11:1-10.

31 Tawfik DS, Profit J, Morgenthaler TI, et al. Physician burnout, well-being, and work unit safety grades in relationship to reported medical errors. Mayo Clin Proc 2018;93:1571-80. doi:10.1016/j. mayocp.2018.05.014

32 Bryson L, Warner-Smith P, Brown P, et al. Managing the work-life roller-coaster: private stress or public health issue? Soc Sci Med 2007;65:1142-53. doi:10.1016/j.socscimed.2007.04.027

33 Garfinkel PE, Bagby RM, Schuller DR, et al. Predictors of success and satisfaction in the practice of psychiatry: a preliminary follow-up study. Can J Psychiatry 2001;46:835-40. doi:10.1177/070674370104600907

34 Kok N, Van Gurp J, van der Hoeven JG, et al. Complex interplay between moral distress and other risk factors of burnout in ICU professionals: findings from a cross-sectional survey study. BMJ Qual Saf 2021. doi:10.1136/bmjqs-2020-012239. [Epub ahead of print: 29 Jun 2021]

35 Cheng C, Bartram T, Karimi L, et al. The role of team climate in the management of emotional labour: implications for nurse retention. $J$ Adv Nurs 2013;69:2812-25. doi:10.1111/jan.12202

36 Kivimäki M, Vanhala A, Pentti J, et al. Team climate, intention to leave and turnover among hospital employees: prospective cohort study. BMC Health Serv Res 2007;7:170. doi:10.1186/1472-6963-7-170

37 Bakker AB, Emmerik Hvan, Euwema MC. Crossover of burnout and engagement in work teams. Work Occup 2006;33:464-89. doi:10.1177/0730888406291310 